\title{
Sensitivity of Food-Based Recommendations Developed Using Linear Programming to Model Input Data in Young Kenyan Children
}

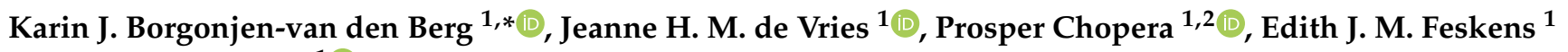 \\ and Inge D. Brouwer ${ }^{1}$ (D) \\ 1 Division of Human Nutrition and Health, Wageningen University, \\ P.O. Box 17, 6700 AA Wageningen, The Netherlands; jeanne.devries@wur.nl (J.H.M.d.V.); \\ pchopera@gmail.com (P.C.); edith.feskens@wur.nl (E.J.M.F.); inge.brouwer@wur.nl (I.D.B.) \\ 2 Department of Nutrition Dietetics and Food Science, Faculty of Science, University of Zimbabwe, Mt Pleasant, \\ Harare P.O. Box MP 167, Zimbabwe \\ * Correspondence: karin.borgonjen@wur.nl
}

check for updates

Citation: Borgonjen-van den Berg, K.J.; de Vries, J.H.M.; Chopera, P.; Feskens, E.J.M.; Brouwer, I.D Sensitivity of Food-Based

Recommendations Developed Using Linear Programming to Model Input Data in Young Kenyan Children. Nutrients 2021, 13, 3485. https:// doi.org/10.3390/nu13103485

Academic Editor: Megan A. McCrory

Received: 18 July 2021

Accepted: 29 September 2021

Published: 30 September 2021

Publisher's Note: MDPI stays neutral with regard to jurisdictional claims in published maps and institutional affiliations.

Copyright: (c) 2021 by the authors. Licensee MDPI, Basel, Switzerland. This article is an open access article distributed under the terms and conditions of the Creative Commons Attribution (CC BY) license (https:/ / creativecommons.org/licenses/by/ $4.0 /)$.

\begin{abstract}
Food-based recommendations (FBR) developed using linear programming generally use dietary intake and energy and nutrient requirement data. It is still unknown to what extent the availability and selection of these data affect the developed FBR and identified problem nutrients. We used $24 \mathrm{~h}$ dietary recalls of 62 Kenyan children (4-6 years of age) to analyse the sensitivity of the FBR and problem nutrients to (1) dietary intake data, (2) selection criteria applied to these data and (3) energy and nutrient requirement data, using linear programming (Optifood(C), by comparing a reference scenario with eight alternative scenarios. Replacing reported by estimated consumption frequencies increased the recommended frequencies in the FBR for most food groups while folate was no longer identified as a problem nutrient. Using the 10-90th instead of the 5-95th percentile of distribution to define minimum and maximum frequencies/week decreased the recommended frequencies in the FBR and doubled the number of problem nutrients. Other alternative scenarios negligibly affected the FBR and identified problem nutrients. Our study shows the importance of consumption frequencies for developing FBR and identifying problem nutrients by linear programming. We recommend that reported consumption frequencies and the 5-95th percentiles of distribution of reported frequencies be used to define the minimum and maximum frequencies.
\end{abstract}

Keywords: sensitivity analysis; linear programming; food-based dietary guidelines; 24 h dietary recall; consumption frequency; low- and middle-income countries

\section{Introduction}

Healthy diets are vital to preventing undernutrition, micronutrient deficiencies and overnutrition which are still widespread public health problems [1]. While some progress has been made on decreasing the prevalence of undernutrition (including stunting and wasting), micronutrient deficiencies persist and the prevalence of overweight, obesity and diet-related non-communicable diseases due to malnutrition are increasing across the globe-rising the fastest in low-income countries [2,3]. Targeting poor diets is one of the major strategies to reverse malnutrition in all its forms and prevent related noncommunicable diseases. However, the challenge is to move toward healthy diets that are notably more diverse with a greater proportion of micronutrient-dense foods [4].

Required changes towards healthy diets can be facilitated by food-based dietary guidelines (FBDG). FBDG are science-based recommendations intended for consumer information. These are used to inform the general population on how to compose a healthy diet that provides adequate amounts of foods and nutrients to prevent deficiencies and 
diet-related diseases. FBDG contain short evidence-based messages expressed in terms of foods to be consumed [5,6], often combined with visuals. The importance of developing FBDG per country for different age groups has been emphasised by the World Health Organisation (WHO) and the Food and Agriculture Organisation (FAO) since 1992 [7]. Still, currently only 93 out of 226 countries have officially endorsed FBDG by the government, including just 7 countries in Africa [8].

In the absence of national government-endorsed FBDG, food-based recommendations (FBR) have been developed to promote certain foods for specific purposes, regions, sex and age groups amongst others. In previous years, the linear programming approach was used to develop FBR in various African countries [9-14]. This approach uses information on existing food habits with the advantage that the developed FBR, if adopted, will improve nutrient intake with minimal deviation from the habitual diet while considering nutritional constraints such as energy requirements and price. Therefore, it is generally assumed that such developed recommendations will be acceptable and affordable for the targeted populations. In addition, problem nutrients-nutrients for which nutrient adequacy cannot be achieved using local foods available — can be objectively identified and can guide towards alternative additional strategies needed to fulfil nutrient adequacy [15].

Linear programming requires model input data such as energy and nutrient goals as well as dietary intake data. The model input data depend on the availability and selection of such data. Energy and nutrient goals depend on the source of requirement data, such as WHO/FAO, European Food Safety Authority (EFSA) or Institute of Medicine (IoM) [16-19]. In addition, other model input data, such as a list of commonly consumed foods, consumed amounts per food per day and minimum and maximum frequency of consumption per food are extracted from available local dietary intake data of the target population, often collected using the $24 \mathrm{~h}$ dietary recall method [20,21]. The number of participants, number of $24 \mathrm{~h}$ recalls per participant as well as availability of additional information per food (such as frequency of consumption) will affect the model input data. In addition to the availability of dietary intake data, model input data depends on selection criteria applied to the dietary intake data. Selection criteria are used to choose commonly consumed foods from all foods consumed as well as to define the minimum and maximum frequency per food, which determines the boundaries of the modelling. Different selection criteria are used in various studies and may affect the outcomes of the modelling and the resulting FBR and identified problem nutrients.

Sensitivity of the developed FBR and of identified problem nutrients to these choices is often described only in general terms in the discussion of papers using linear programming [9-12,22-26], but rarely quantified by sensitivity analysis $[9,23,25,26]$. It is therefore unknown what effect the choice of dietary intake data, selection criteria and energy and nutrient requirement data have on the final results of linear programming. To determine the robustness of the developed FBR and the type and number of identified problem nutrients using linear programming, sensitivity analyses are needed.

Using dietary intake data of Kenyan children 4-6 years of age, in this methodological paper we present the sensitivity of the developed FBR and the type and number of problem nutrients to (1) quality of dietary intake data, (2) selection criteria applied to dietary intake data and (3) energy and nutrient requirement data using linear programming. To address this sensitivity may be useful for the design of future linear programming studies in lowand middle-income countries.

\section{Materials and Methods}

\subsection{Study Design}

Optifood $(C$ was used to develop FBR and to identify problem nutrients using linear programming [27]. One reference scenario was compared with eight alternative scenarios. In each alternative scenario one aspect of the dietary intake data, selection criteria, or energy and nutrient requirement data was changed while maintaining other aspects unchanged (Figure 1). 


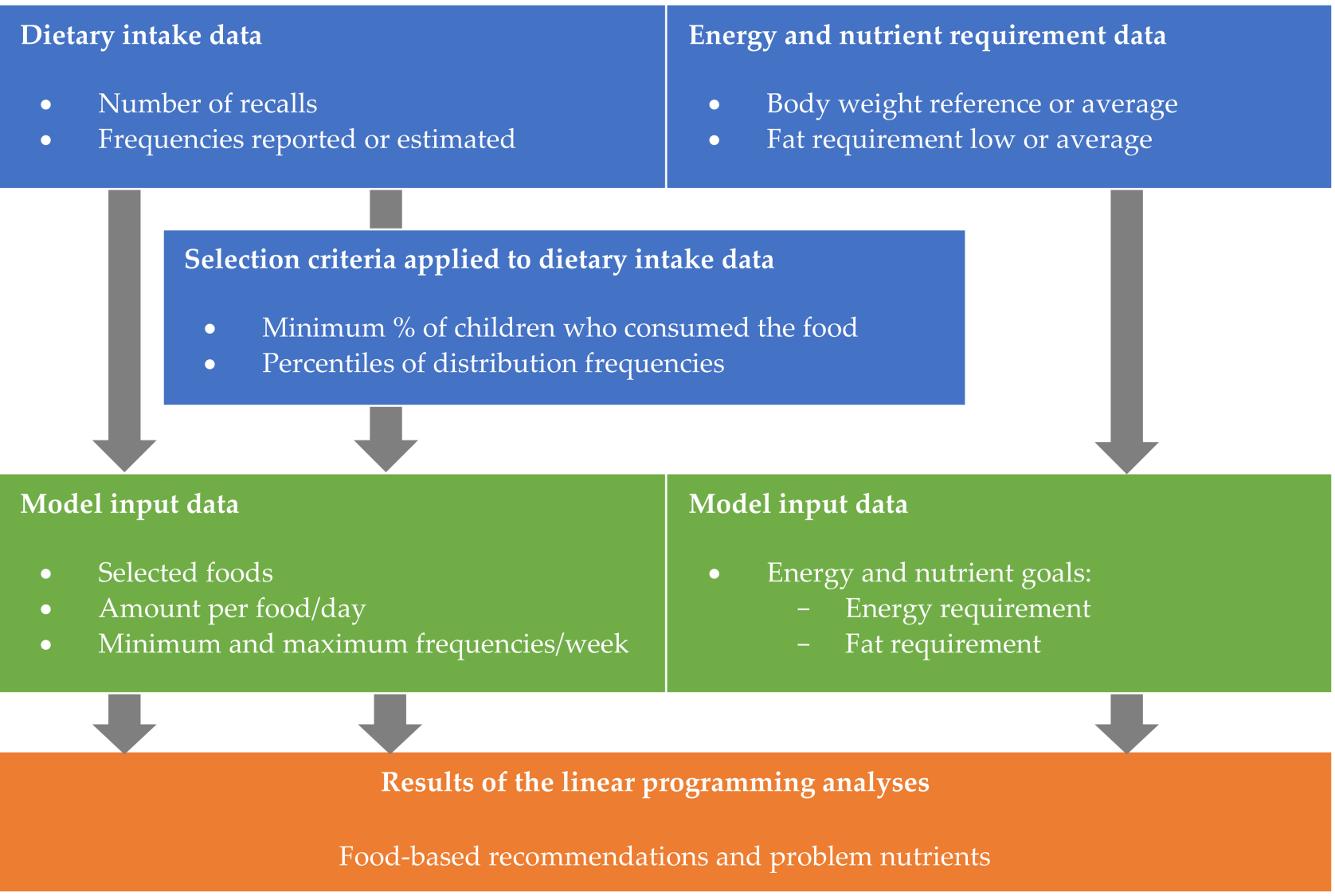

Figure 1. Illustration of the study design: to analyse the sensitivity of the developed FBR and type and number of problem nutrients to (1) quality of dietary intake data, (2) selection criteria applied to this data and (3) energy and nutrient requirement data using linear programming and $24 \mathrm{~h}$ dietary recalls of Kenyan children 4-6 years of age.

We used dietary intake data collected in a subsample of 112 randomly selected nonbreastfed children 2-6 years of age, who were part of a larger randomised controlled double blind trial investigating the effectiveness of zinc-fortified drinking water on increasing zinc status [28]. The study was conducted in Kisumu West District, Nyanza province in Western Kenya, near Lake Victoria. Dietary intake data were collected over a period of 2 weeks in August 2014 during the pre-harvest season to evaluate dietary intake on population level. For the current linear programming study only the dietary intake data of children 4-6 years of age $(n=62)$ was used since these children constituted the largest age group in the dataset with similar nutrient requirements.

\subsection{Dietary Assessment and Anthropometry}

Two quantitative multiple pass $24 \mathrm{~h}$ recalls per child were conducted on non-consecutive days [21,29]. For the total population, recalls were evenly distributed over all days of the week and randomly assigned to well-trained interviewers who fluently spoke the local language. Details on the dietary assessment method as well as anthropometry are described elsewhere [23].

In summary, all foods and drinks consumed by the child the day before the interview (over a $24 \mathrm{~h}$ period) were listed. To assess amounts per food, ingredient and beverage, similar foods of comparable size were weighed or when the actual food was not available in the household, amounts were estimated in monetary value, volume, household measures or general sizes (small, medium, large). Frequency per food was reported as the number of days each food was consumed by the child over the previous 7 days. Conversion and waste factors were used to convert alternative amounts into grams. Standard recipes were composed when details of recalled dishes were missing. 
A food composition table was specifically compiled for this study, based on the national food composition table of Kenya [30], and supplemented with data from other food composition tables [31-34]. United States Department of Agriculture (USDA) retention factors [35] were applied to raw ingredients and foods to account for nutrient losses during preparation. The nutrient calculation program Compl-eat (version 1.0, Wageningen University, Wageningen, The Netherlands) including the compiled food composition table was used to calculate energy and nutrient intake per child per day. Average dietary intake, coefficient of variation and percentage children with an average intake below estimated average requirement (EAR derived from $\mathrm{FAO} / \mathrm{WHO}$ recommended nutrient intakes (RNI) using conversion factors from IoM) [36], were calculated for energy and the nutrients of interest (using SPSS Statistics 25): total fat, total protein, calcium, iron, zinc, thiamin, riboflavin, niacin, vitamin B6, folate, vitamin B12, vitamin $C$ and vitamin $A$ [37].

Body weight and height were measured, and z-scores were calculated for height for age (HAZ) and BMI for age (BAZ) using WHO Anthro plus (version 3.2.2, www.who. int/childgrowth/software/en/ (accessed on 23 June 2017)). Stunting and thinness were defined as HAZ or BAZ less than -2 SD respectively.

The effectiveness trial was registered at www.clinicaltrials.gov (NCT0216223) and approved by the Ethical Review Committee of Kenyatta National Hospital/Nairobi University (KNH-ERC/A/335) and ETH Zurich Ethical review committee (EK 2013-N-31). Before the start of the study, written informed consent was obtained from the head of the household and the caregiver on behalf of the child.

\subsection{Determining Diet Models for Various Scenarios}

For the reference scenario, model input data were defined using dietary intake data from both $24 \mathrm{~h}$ recalls per child. These model input data consisted of (1) a list of noncondiment foods reported by $\geq 3 \%$ of the children in one of the two recalls. Using $3 \%$ instead of the generally used 5\% [9] allowed us to increase the number of foods in the modelling, as the variety of foods in the diet of our population was low; (2) median daily amount for each selected food for those consuming the food; (3) the minimum and maximum frequency of consumption per week for each food and (sub-) food group. Minimum and maximum frequency per week were defined as 5th and 95th percentiles, respectively, of the reported frequencies per food per week [25]. Reported frequencies of both recalls were included independently in the distribution estimation. Foods that were not present in one recall were assumed not to be consumed during the 7 days prior to that recall. All modelled diets had to meet the energy requirement which was calculated using the mean body weight of the target group and the FAO/WHO/United Nations University (UNU) algorithm for estimating energy requirements [16]. Nutrient goals were set as recommended nutrient intakes (RNI) defined by FAO/WHO $[17,38,39]$ for the nutrients of interest. Since the fat requirement was defined as a range of $25-35 \%$ of energy $(\mathrm{en} \%)$, in the reference scenario the average requirement of $30 \mathrm{en} \%$ was used. Low bioavailability for iron and zinc (5\% and 15\%, respectively) was assumed for an unrefined cereal-based diet with high levels of phytate. Energy and nutrient composition per $100 \mathrm{~g}$ of the selected foods were adopted from the compiled food composition table.

Eight alternative scenarios were defined to test the sensitivity of the developed FBR and the type and number of problem nutrients (Table 1). Per alternative scenario, one of the selection criteria used in the reference scenario was replaced by an alternative criteria. The first three alternative scenarios A, B and C were compared with the reference scenario to evaluate the impact of dietary intake data on FBR and problem nutrients. In the first alternative scenario A, the reported frequencies per food per week used in the reference scenario were replaced by estimated frequencies per food per child. These were based on the number of days the food subgroup appeared in the two recalls, converted to a frequency per week and the proportion of children that consumed the food. This latter method to estimate frequencies per food per week is commonly used to define model input data for Optifood $^{\odot}[9,11,13,23,25]$. In the second alternative scenario B only the first of the two $24 \mathrm{~h}$ 
recalls was used to define the model input data. The third alternative scenario $C$ was a combination of scenario A and B where estimated frequencies per week were combined with only the first recalls.

Table 1. Reference scenario and alternative scenarios A-H used to define model input data for linear programming.

\begin{tabular}{|c|c|c|c|}
\hline \multirow{2}{*}{ Model Input Data } & \multirow{2}{*}{ Selection Criteria } & \multicolumn{2}{|c|}{ Frequencies } \\
\hline & & Reported & Estimated \\
\hline \multirow[t]{2}{*}{ Amount per food/day } & 2 dietary recalls & Reference scenario & Scenario A \\
\hline & 1 dietary recall & Scenario B & Scenario C \\
\hline \multirow[t]{3}{*}{ Selected foods } & $\geq 3 \%$ of children consumed the food & Reference scenario & \\
\hline & $\geq 10 \%$ of children consumed the food & Scenario D & \\
\hline & All foods consumed & Scenario E & \\
\hline \multirow{2}{*}{$\begin{array}{l}\text { Min and max frequencies/week } \\
\text { per food and food (sub)group }\end{array}$} & 5-95th percentile & Reference scenario & \\
\hline & 10-90th percentile & Scenario F & \\
\hline \multirow[t]{2}{*}{ Energy requirement } & Based on average body weight & Reference scenario & \\
\hline & Based on reference body weight & Scenario G & \\
\hline \multirow[t]{2}{*}{ Fat requirement } & 30 en $\%$ (mean) and average body weight & Reference scenario & \\
\hline & 25 en\% (low) and average body weight & Scenario $\mathrm{H}$ & \\
\hline
\end{tabular}

Alternative scenarios D, E and $\mathrm{F}$ were compared with the reference scenario to evaluate the impact of selection criteria applied to dietary intake data on FBR and problem nutrients. In the alternative scenario $\mathrm{D}$, only non-condiment foods consumed by $\geq 10 \%$ of the children were selected in an attempt to stay closer to the average food pattern. In alternative scenario $\mathrm{E}$, all non-condiment foods consumed were used to define the model input data, irrespective of how many children consumed these foods. In alternative scenario F minimum and maximum frequency per week for selected foods and food (sub)groups were narrowed and defined as 10th and 90th percentiles, respectively, of the reported frequencies per food per week to remain closer to the average food pattern.

The last two alternative scenarios $\mathrm{G}$ and $\mathrm{H}$ were compared with the reference scenario to evaluate the impact of energy and nutrient requirement data on FBR and problem nutrients. In alternative scenario $\mathrm{G}$ energy requirements were estimated using the $\mathrm{FAO} / \mathrm{WHO} / \mathrm{UNU}$ algorithm including reference body weight instead of mean body weight as in the reference scenario [40]. In the alternative scenario $\mathrm{H}$, the nutrient goal for fat was defined as the lower tail of the fat requirement ( $25 \mathrm{en} \%)$.

\subsection{Linear Programming Analyses}

Linear programming analyses were performed in Optifood $^{\odot}$, a linear programming approach to model realistic diets for target populations and to objectively identify problem nutrients [27]. For the reference scenario as well as the 8 alternative scenarios, 3 modules were run per scenario.

Module I was run to ensure that the model input data were generating realistic and feasible diets. Module II was run to develop the best-optimised diet (draft FBR) reaching nutrient adequacy for as many nutrients as possible, limited by the minimum and maximum frequencies per week and the energy requirement. Module III was run to identify problem nutrients, nutrients that were unable to reach $100 \% \mathrm{RNI}$ in the maximised diet. One maximised diet for each nutrient of interest was modelled and included the most nutrient dense foods within each food group to verify the highest possible nutrient intake of that nutrient. The draft FBR developed in module II as well as the problem nutrients defined in module III were compared between the alternative scenarios and the reference scenario. 


\section{Results}

\subsection{Characteristics and Dietary Intake of the Study Population}

Slightly more girls $(n=36)$ than boys $(n=26)$ were included in the dietary assessment study (Table 2). Body weight and height were measured in 60 out of 62 children, of whom $13(22 \%)$ were stunted. The prevalence of stunting was higher in boys $(n=8)$ than in girls $(n=5)$ and no children were underweight.

Table 2. Characteristics of the Kenyan children in the study population $(n=62)$ including median intake per day and coefficients of variation for energy and the nutrients of interest ${ }^{1}$.

\begin{tabular}{|c|c|c|c|c|c|c|}
\hline & & Median $^{1}$ & $25-75$ th Perc $^{1}$ & CV\%wtn ${ }^{2}$ & CV\%btn ${ }^{3}$ & $\%$ below EAR ${ }^{4}$ \\
\hline \multicolumn{7}{|c|}{ Background } \\
\hline Sex, girls & $n(\%)$ & $36(58)$ & & & & \\
\hline Age & $\mathrm{Y}$ & 5.3 & $4.6-6.0$ & & & \\
\hline \multicolumn{7}{|c|}{ Anthropometrics ${ }^{5}$} \\
\hline Body weight & $\mathrm{kg}$ & 16.9 & $15.5-18.4$ & & & \\
\hline Height for age 6 & z-score & -1.1 & $-1.9-0.4$ & & & \\
\hline Stunted ${ }^{6}$ & $\mathrm{~N}$ & 13 & & & & \\
\hline BMI for age 6 & z-score & 0.0 & $-0.6-0.6$ & & & \\
\hline Underweight ${ }^{6}$ & $\mathrm{~N}$ & 0 & & & & \\
\hline \multicolumn{7}{|c|}{ Dietary intake of nutrients ${ }^{7}$} \\
\hline Energy & $\mathrm{kcal} / \mathrm{d}$ & 1489 & $1172-1852$ & 29.8 & 22.4 & 34 \\
\hline Protein & $\mathrm{g} / \mathrm{d}$ & 35.8 & $28.3-46.5$ & 37.9 & 23.7 & 2 \\
\hline Fat & $\mathrm{g} / \mathrm{d}$ & 39.4 & $29.7-54.4$ & 59.1 & 15.4 & 40 \\
\hline Thiamin & $\mathrm{mg} / \mathrm{d}$ & 0.78 & $0.58-1.11$ & 51.4 & 22.5 & 18 \\
\hline Riboflavin & $\mathrm{mg} / \mathrm{d}$ & 0.49 & $0.36-0.70$ & 54.6 & 36.7 & 52 \\
\hline Niacin & $\mathrm{mg} / \mathrm{d}$ & 5.05 & $4.03-6.38$ & 50.1 & 0 & 68 \\
\hline Vitamin B6 & $\mathrm{mg} / \mathrm{d}$ & 0.64 & $0.52-0.91$ & 53.1 & 0 & 21 \\
\hline Folate & ug/d & 112 & 74-159 & 62.5 & 32.3 & 76 \\
\hline Vitamin B12 & $\mathrm{ug} / \mathrm{d}$ & 0.88 & $0.48-1.57$ & 104.2 & 48.8 & 58 \\
\hline Vitamin C & $\mathrm{mg} / \mathrm{d}$ & 29.8 & $18.5-43.1$ & 90.2 & 31.0 & 37 \\
\hline Vitamin A (RAE) & $\mathrm{ug} / \mathrm{d}$ & 95.5 & $49.1-150.0$ & 98.3 & 69.2 & 98 \\
\hline Calcium & $\mathrm{mg} / \mathrm{d}$ & 511 & $300-669$ & 68.6 & 50.8 & 48 \\
\hline Iron & $\mathrm{mg} / \mathrm{d}$ & 10.6 & $8.8-14.4$ & 48.7 & 31.8 & 63 \\
\hline Zinc & $\mathrm{mg} / \mathrm{d}$ & 5.26 & $4.04-7.10$ & 48.2 & 24.0 & 82 \\
\hline
\end{tabular}

${ }^{1}$ Values indicate median and 25-75th percentile unless indicated otherwise. ${ }^{2}$ Within-person coefficient of variation. ${ }^{3}$ Between-person coefficient of variation. ${ }^{4}$ EAR: Estimated average requirement [36]. ${ }^{5}$ Anthropometry was measured in 60 children. ${ }^{6}$ Children were classified as stunted or underweight if their HAZ or BAZ respectively were less than - 2 SD according to WHO child growth standards (<60 months) and WHO reference 2007 (>61 months) [40,41]. ${ }^{7}$ Average of 2 recalls. N: number of children; Y: years.

Dietary assessment included two $24 \mathrm{~h}$ dietary recalls per child with, on average, 8 days between the first and second recall and a total of 124 recalls. In both recalls, 86 different non-condiment food items were reported in the dietary recalls, of which 64 food items were reported by at least $3 \%$ of the children in at least one of the two recalls. The most commonly consumed foods were maize, tomato, onion, milk, vegetable oil and sugar (consumed by $>80 \%$ of the children). Median consumption frequency was highest for vegetables with two types of vegetables consumed per day (Supplementary Table S1). The median energy intake was $1489 \mathrm{kcal} /$ day (25-75th percentiles: 1172-1852 kcal/day). For seven nutrients the median intake was below the EAR for $>50 \%$ of the children. Vitamin A, zinc and folate had the highest percentage of children below EAR $(98 \%, 82 \%$ and $76 \%$ respectively). The within-person coefficient of variation for this population was highest for vitamins B12, A and C (104\%, 98\% and 90\% respectively). Vitamin A, calcium and vitamin B12 had the highest between-person coefficient of variation (69\%, 51\% and $49 \%$ respectively) (Table 2). 


\subsection{The Effects of Scenarios on FBR and Problem Nutrients}

Developed draft FBR for the reference scenario consisted of added fats 7 times/week, dairy products 8 times/week, fruits 7 times/week, grains and grain products 21 times/week, legumes, nuts and seeds 4 times/week, meat, fish and eggs 7 times/week and vegetables 28 times/week (Table 3). Draft FBR in alternative scenarios were mainly affected when the reported frequencies were replaced by the estimated frequencies (scenario $\mathrm{A}$ including 2 recalls and scenario $C$ including 1 recall). The recommended frequencies per week in the draft FBR increased for most food groups in both scenarios compared to the reference draft FBR. Furthermore, in scenario F, when the tails of the distribution of consumption frequencies per week of the foods and food (sub)groups were narrowed to the 10th and 90th percentiles, the recommended frequencies per week decreased for the fruits, meat, fish and eggs and vegetables food groups compared to the reference draft FBR, and the legumes, nuts and seeds food group was no longer included. The effects of the other alternative scenarios on the draft FBR were negligible.

Problem nutrients in the reference scenario were folate (94\% RNI), vitamin A (56\% RNI) and zinc ( $86 \%$ RNI) (Table 4). The number of problem nutrients decreased from 3 to 2 when the reported frequencies were replaced by estimated frequencies in scenarios A and C, since folate was no longer identified as a problem nutrient $(130 \%$ and $128 \%$ RNI respectively). Total fat did not reach the goal of $30 \mathrm{en} \%$ when only foods consumed by at least $10 \%$ of the children were included (scenario D) and when the 10th and 90th percentiles were used to define the minimum and maximum frequencies of consumption per week (scenario F). However, the fat content of the maximised diet remained within the requirement range of 25-35 en\% (respectively $29 \mathrm{en} \%$ and $28 \mathrm{en} \%$ ). Moreover, in the latter scenario (scenario $\mathrm{F}$ ), the highest number of problem nutrients were identified including riboflavin, niacin, folate, vitamin B12, vitamin $\mathrm{A}$, iron and zinc.

\subsection{The Effects of Scenarios on Model Input Data}

Only 37 out of 64 commonly consumed foods were included in the food list in the reference scenario. This is because the frequency of consumption per week was 0 in the 95th percentile for the 27 excluded foods (Table 5). Alternative scenario A, using estimated frequencies, contained the highest number of foods in the food list $(n=59)$, while scenario $\mathrm{F}$, using the 90th percentile to define maximum frequencies per week, contained the lowest number of foods in the food list $(n=26)$. In scenario $E$, which used all 86 foods consumed, only 37 foods were included in the food list as the frequency of consumption of the excluded foods consumed by less than $3 \%$ of the children was 0 in the 95th percentile. This resulted in the model input data being identical to the reference scenario. The number of foods reported by at least $3 \%$ of the children decreased from 64 using two recalls to 50 using only the first recalls (scenarios B and C). From the 50 foods reported in the first recall, daily amount per food remained the same for 12 foods, increased for 18 foods and decreased for 20 foods compared to the daily amount per food using two $24 \mathrm{~h}$ recalls (Supplementary Table S2).

The minimum and maximum consumption frequencies per week used as model input data are shown in Supplementary Table S3. Nearly all recommended frequencies in the draft FBR were equal to the maximum consumption frequencies per week either defined as the 95th percentile (reference scenario) or the 90th percentile of distribution (scenario F). In addition, either minimum and/or maximum frequency per week increased for all food groups when estimated frequencies were used (scenarios A and C) compared to reported frequencies in the reference scenario. 
Table 3. Draft FBR in frequency per week for the reference scenario and alternative scenarios defined in Optifood module 2 for Kenyan children, 4-6 years of age.

\begin{tabular}{|c|c|c|c|c|c|c|c|c|c|}
\hline & $\begin{array}{l}\text { Reference } \\
\text { Scenario }^{1}\end{array}$ & $\begin{array}{l}\text { Scenario A } \\
\text { Est Freq }^{2}\end{array}$ & $\begin{array}{c}\text { Scenario B } \\
\text { Rp Freq }^{3} \\
1 \text { Recall }\end{array}$ & $\begin{array}{c}\text { Scenario C } \\
\text { Est Freq }^{2} \\
1 \text { Recall }\end{array}$ & $\begin{array}{c}\text { Scenario D } \\
\geq 10 \% \text { Cons }\end{array}$ & $\begin{array}{l}\text { Scenario E } \\
\text { All Foods }\end{array}$ & $\begin{array}{c}\text { Scenario F } \\
\text { 10-90th Perc }\end{array}$ & $\begin{array}{l}\text { Scenario G } \\
\text { Ref Weight }^{6}\end{array}$ & $\begin{array}{l}\text { Scenario H } \\
25 \text { en } \% \text { Fat }\end{array}$ \\
\hline Food group ${ }^{7}$ & \multicolumn{9}{|c|}{ Number of daily amounts per week } \\
\hline Added fats & 7 & 4 & 6 & 4 & 7 & 7 & 7 & 7 & 5 \\
\hline Added sugars & 0 & 4 & 1 & 7 & 0 & 0 & 4 & 0 & 0 \\
\hline $\begin{array}{c}\text { Bakery and } \\
\text { breakfast cereals } 8\end{array}$ & 0 & 0 & 0 & 0 & - & 0 & - & 2 & 2 \\
\hline Dairy products & 8 & 11 & 12 & 14 & 7 & 8 & 7 & 8 & 8 \\
\hline Fruits & 7 & 7 & 7 & 10 & 7 & 7 & 2 & 7 & 7 \\
\hline $\begin{array}{l}\text { Grains and grain } \\
\text { products }\end{array}$ & 21 & 12 & 19 & 11 & 21 & 21 & 21 & 22 & 22 \\
\hline $\begin{array}{l}\text { Legumes, nuts } \\
\text { and seeds } 8\end{array}$ & 4 & 7 & 4 & 3 & 3 & 4 & - & 4 & 4 \\
\hline $\begin{array}{l}\text { Meat, fish } \\
\text { and eggs }\end{array}$ & 7 & 11 & 5 & 14 & 7 & 7 & 3 & 7 & 7 \\
\hline $\begin{array}{l}\text { Starchy roots and } \\
\text { other starchy } \\
\text { plant foods }\end{array}$ & - & 3 & 0 & 3 & - & - & - & - & - \\
\hline
\end{tabular}

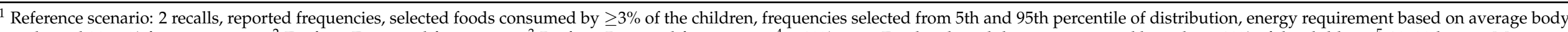

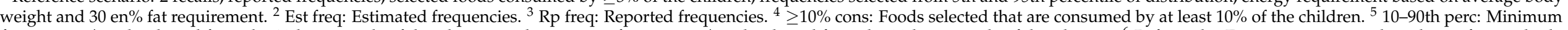

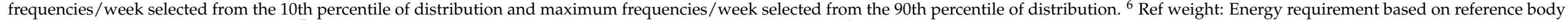
weight of the target group (4-6 years). ${ }^{7}$ See Supplementary Table S2 for more details on classification of foods. ${ }^{8}$-: not included in the model. 
Table 4. Identified problem nutrients as \% of RNI in a maximised diet per nutrient for reference scenario and alternative scenarios for Kenyan children, 4-6 years of age.

\begin{tabular}{|c|c|c|c|c|c|c|c|c|c|}
\hline & \multicolumn{9}{|c|}{ Maximised Diet } \\
\hline & $\begin{array}{l}\text { Reference } \\
\text { Scenario }{ }^{1}\end{array}$ & $\begin{array}{c}\text { Scenario A } \\
\text { Est Freq }^{2}\end{array}$ & $\begin{array}{c}\text { Scenario B } \\
\text { Rp Freq }^{3}, 1 \\
\text { Recall }\end{array}$ & $\begin{array}{c}\text { Scenario C } \\
\text { Est Freq }^{2}, 1 \\
\text { Recall }\end{array}$ & $\begin{array}{c}\text { Scenario D } \\
\geq 10 \% \text { Cons }\end{array}$ & $\begin{array}{l}\text { Scenario E } \\
\text { All Foods }\end{array}$ & $\begin{array}{c}\text { Scenario F } \\
\text { 10-90th Perc }\end{array}$ & $\begin{array}{c}\text { Scenario G } \\
\text { Ref Weight }^{6}\end{array}$ & $\begin{array}{l}\text { Scenario H } \\
25 \text { en } \% \text { Fat }\end{array}$ \\
\hline Nutrient & & & & & $\%$ RNI & & & & \\
\hline Protein & 371 & 450 & 411 & 466 & 364 & 371 & 286 & 356 & 371 \\
\hline Fat $(\mathrm{en} \%)^{7}$ & 33 & 51 & 36 & 35 & $29^{9}$ & 33 & $28^{9}$ & 30 & 33 \\
\hline Thiamin & 220 & 209 & 282 & 230 & 216 & 220 & 177 & 235 & 220 \\
\hline Riboflavin & 134 & 188 & 179 & 215 & 115 & 134 & $94^{8}$ & 136 & 134 \\
\hline Niacin & 103 & 103 & 122 & 118 & 102 & 103 & $77^{8}$ & 106 & 103 \\
\hline Vitamin B6 & 177 & 183 & 196 & 207 & 177 & 177 & 149 & 192 & 177 \\
\hline Folate & $94^{8}$ & 130 & $96^{8}$ & 128 & $86^{8}$ & $94^{8}$ & $52^{8}$ & $96^{8}$ & $94^{8}$ \\
\hline Vitamin B12 & 110 & 205 & 173 & 285 & 101 & 110 & $86^{8}$ & 111 & 110 \\
\hline Vitamin C & 196 & 296 & 221 & 438 & 195 & 196 & 110 & 196 & 196 \\
\hline Vitamin A & $56^{8}$ & $72^{8}$ & $69^{8}$ & $84^{8}$ & $53^{8}$ & $56^{8}$ & $28^{8}$ & $56^{8}$ & $56^{8}$ \\
\hline Calcium & 136 & 225 & 229 & 342 & 126 & 136 & 103 & 136 & 136 \\
\hline Iron & 123 & 136 & 135 & 140 & 119 & 123 & $97^{8}$ & 129 & 123 \\
\hline Zinc & $86^{8}$ & $76^{8}$ & $89^{8}$ & $79^{8}$ & $83^{8}$ & $86^{8}$ & $66^{8}$ & $92^{8}$ & $86^{8}$ \\
\hline
\end{tabular}

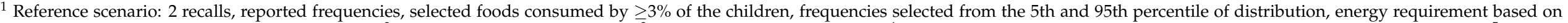

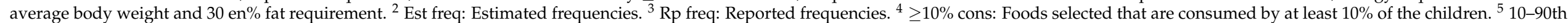

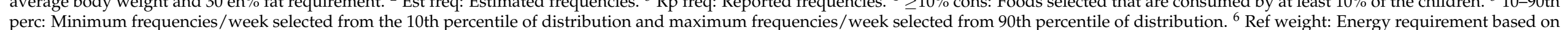

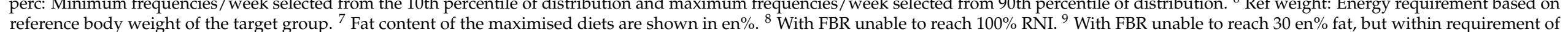
$25-35$ en $\%$. 
Table 5. Number of foods consumed and included in the food list per scenario for Kenyan children, 4-6 years of age.

\begin{tabular}{|c|c|c|c|}
\hline & & Consumed & In Food List ${ }^{1}$ \\
\hline Scenario & & \multicolumn{2}{|c|}{ Number of Foods } \\
\hline Reference scenario $^{2}$ & & 64 & 37 \\
\hline Scenario A: & Estimated frequencies & 64 & 59 \\
\hline Scenario B: & 1 recall & 50 & 44 \\
\hline Scenario C: & 1 recall, Est freq ${ }^{3}$ & 50 & 48 \\
\hline Scenario D: & $\geq 10 \%$ consumed ${ }^{4}$ & 33 & 33 \\
\hline Scenario E: & All foods consumed & 86 & 37 \\
\hline Scenario F: & 10-90th percentile ${ }^{5}$ & 64 & 26 \\
\hline
\end{tabular}

${ }^{1}$ Food is included in food list when the frequency of consumption $>0$ in the 95th percentile (or 90th percentile in scenario F). ${ }^{2}$ Reference scenario: 2 recalls, reported frequencies, selected foods consumed by $\geq 3 \%$ of the children, frequencies selected from 5 th and 95 th percentile of distribution. ${ }^{3}$ Est freq: Estimated frequencies. ${ }^{4} \geq 10 \%$ cons: Foods selected that are consumed by at least $10 \%$ of the children. ${ }^{5} 10-90$ th percentile: Minimum frequencies/week selected from the 10th percentile of distribution and maximum frequencies/week selected from the 90th percentile of distribution.

The estimated energy requirement in scenario $\mathrm{G}$ increased from $1256 \mathrm{kcal} /$ day to $1427 \mathrm{kcal} /$ day when reference body weight $(19.2 \mathrm{~kg})$ instead of the mean actual body weight $(16.9 \mathrm{~kg})$ was used to define the energy requirement of the target group. Due to the increased body weight and energy requirement, the absolute estimated protein requirement rose from $12 \mathrm{~g}$ to $13 \mathrm{~g}$ and the absolute fat requirement from $42 \mathrm{~g}$ to $48 \mathrm{~g}$. When the fat requirement was defined as $25 \mathrm{en} \%$ (scenario $\mathrm{H}$ ) instead of $30 \mathrm{en} \%$ in the reference scenario, the absolute fat requirement decreased from $42 \mathrm{~g}$ to $35 \mathrm{~g}$.

\section{Discussion}

To our knowledge, this is the first study that has investigated the sensitivity of FBR and of identified problem nutrients to the selection of dietary intake data, criteria and energy and fat requirements by linear programming. The sensitivity of the results of linear programming to the model input data is often mentioned, but rarely quantified $[9,23,25,26]$.

Our study showed that the results of linear programming, i.e., draft FBR and type and number of problem nutrients, were most sensitive to the consumption frequencies and the percentiles defining minimum and maximum frequencies per week (Table 6). The draft FBR were most affected by the use of estimated frequencies (based on the presence in the $24 \mathrm{~h}$ dietary recalls) instead of reported frequencies. Estimated frequencies increased recommended frequencies of most food (sub)groups in the draft FBR. The number of problem nutrients increased from 3 to 7 when the 10-90th instead of 5-95th percentiles were used. The results of linear programming in our population were less sensitive to the number of recall days per child, criteria to define the food list and selected level of energy and fat requirement.

To compare the alternative scenarios, we used the draft FBR including the most nutrient-dense foods available within the set of constraints generated in the linear programming analyses in this study (model II results), and not the final FBR (module III analysis). To develop realistic final FBR, recommendations per food (sub)group and food need to be tested and combined (module III analysis), requiring thorough knowledge about local food patterns and therefore the involvement of local experts and policymakers. However, this would introduce additional subjective decisions on the development of FBR, influencing the ability to attribute possible differences in the resulting FBR of the studied scenarios solely to changes in the model input data. 


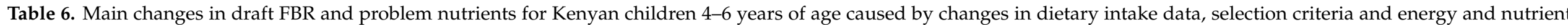
requirement data.

\begin{tabular}{|c|c|c|c|c|c|c|c|c|c|}
\hline & $\begin{array}{l}\text { Reference } \\
\text { Scenario }\end{array}$ & $\begin{array}{l}\text { Scenario A } \\
\text { Est Freq }^{2}\end{array}$ & $\begin{array}{c}\text { Scenario B } \\
\text { Rp Freq }^{3} \\
1 \text { Recall }\end{array}$ & $\begin{array}{c}\text { Scenario C } \\
\text { Est Freq }^{2} \\
1 \text { Recall }\end{array}$ & $\begin{array}{l}\text { Scenario D } \\
\text { (break) } \geq 10 \% \\
\text { Cons } 4\end{array}$ & $\begin{array}{l}\text { Scenario E } \\
\text { All Foods }\end{array}$ & $\begin{array}{c}\text { Scenario F } \\
\text { 10-90th Perc }{ }^{5}\end{array}$ & $\begin{array}{c}\text { Scenario G } \\
\text { Ref Weight }^{6}\end{array}$ & $\begin{array}{l}\text { Scenario H } \\
25 \text { en } \% \text { Fat }\end{array}$ \\
\hline Draft FBR ${ }^{7}$ & $\begin{array}{c}\text { Frequencies per } \\
\text { week }\end{array}$ & \multicolumn{8}{|c|}{ Changes in frequencies and problem nutrients compared to the reference scenario } \\
\hline Added fats & 7 & - & & - & & & & & - \\
\hline Dairy products & 8 & + & + & + & & & & & \\
\hline Fruits & 7 & & & + & & & - & & \\
\hline $\begin{array}{l}\text { Grains and } \\
\text { grain products }\end{array}$ & 21 & - & Negligible & - & Negligible & None & & Negligible & Negligible \\
\hline $\begin{array}{l}\text { Legumes, nuts } \\
\text { and seeds }\end{array}$ & 4 & + & & & & & - & & \\
\hline $\begin{array}{l}\text { Meat, fish } \\
\text { and eggs }\end{array}$ & 7 & + & & + & & & - & & \\
\hline Vegetables & 28 & + & & + & & & - & & \\
\hline Added sugars & 0 & + & + & + & & & + & & \\
\hline $\begin{array}{l}\text { Starchy roots } \\
\text { and other } \\
\text { starchy plant } \\
\text { foods } 8\end{array}$ & - & + & & + & & & & & \\
\hline $\begin{array}{l}\text { Bakery and } \\
\text { breakfast cereals }\end{array}$ & 0 & & & & & & & + & + \\
\hline \multicolumn{10}{|l|}{$\begin{array}{l}\text { Problem } \\
\text { nutrients }\end{array}$} \\
\hline Folate & $\bullet$ & & $\bullet$ & & $\bullet$ & $\bullet$ & $\bullet$ & $\bullet$ & $\bullet$ \\
\hline Vitamin A & $\bullet$ & $\bullet$ & $\bullet$ & $\bullet$ & $\bullet$ & $\bullet$ & $\bullet$ & $\bullet$ & $\bullet$ \\
\hline Zinc & $\bullet$ & $\bullet$ & $\bullet$ & $\bullet$ & $\bullet$ & $\bullet$ & $\bullet$ & $\bullet$ & $\bullet$ \\
\hline Riboflavin & & & & & & & $\bullet$ & & \\
\hline Niacin & & & & & & & $\bullet$ & & \\
\hline Vitamin B12 & & & & & & & $\bullet$ & & \\
\hline Iron & & & & & & & $\bullet$ & & \\
\hline
\end{tabular}

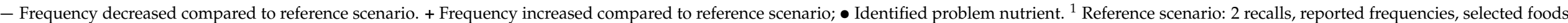

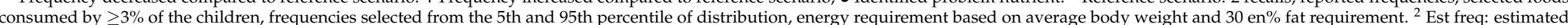

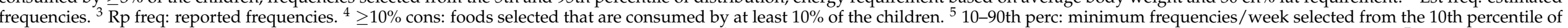

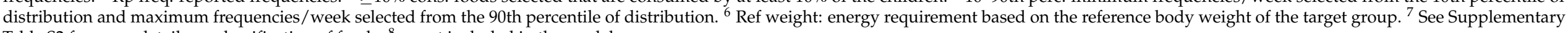
Table S2 for more details on classification of foods. ${ }^{8}-$ : not included in the model 
The $24 \mathrm{~h}$ dietary recall method, used to assess intake, is the preferred method in lowand middle-income countries [21,42]. However, there are random and systematic errors related to this method, such as the memory of the participant, interviewer bias, portion size estimation and nutrient values in the food composition table. Although measurement errors were minimised as much as possible in this study, these errors may have affected the absolute values of dietary intake data, draft FBR and problem nutrients. However, as these errors were present in all scenarios, the comparison between the scenarios was assumed not to be affected.

Using estimated frequencies instead of reported frequencies increased the recommended frequencies of most food (sub)groups in the draft FBR. Estimated frequencies resulted in higher minimum and maximum frequencies per food and food (sub)group used as model input data. Minimum and maximum frequencies were defined using the distribution of consumption frequencies. The distribution of estimated frequencies was estimated per child, with possible frequencies of 7,3.5 and 0 if the food was consumed on both days, 1 of the 2 days or not consumed, respectively. Distribution of reported frequencies was based on the frequencies of foods present in all 124 recalls with all possible frequencies between 0 , if the food was not consumed on that day, and 7 , if the food was consumed every day in the previous 7 days. Using estimated frequencies probably overestimated the maximum frequencies per food and food (sub)group, because the consumption of a food on both days may not necessarily reflect consumption on every day in the previous week. This overestimation of maximum (and not of minimum) consumption frequencies resulted in higher recommended frequencies in the draft FBR. The recommended frequencies may therefore be too high to be acceptable and affordable for the target population.

Although reported frequencies are expected to be more accurate than estimated frequencies, we only asked respondents to report frequencies of the foods they consumed in the recall. Consumption frequencies of foods that were not consumed on one of the recall days were therefore lacking, assuming that these foods were not consumed at all. Therefore, reported frequencies probably underestimated the minimum frequencies of foods and food (sub)groups. This could have affected the scenarios comparing the reported frequencies with the estimated frequencies. However, as the draft FBR in the scenarios with reported frequencies were not limited by the minimum consumption frequencies, comparison of the draft FBR and problem nutrients was assumed to be unaffected.

Although the missing consumption frequencies were not expected to affect the results in this study, they may affect results in future research. To overcome this, a propensity questionnaire could be added to the $24 \mathrm{~h}$ dietary recall to collect consumption frequencies of irregularly consumed foods. The propensity questionnaire enables the researcher to include irregularly consumed, nutrient-dense foods in the model, which may decrease the number of problem nutrients $[43,44]$.

In our study population, the 5-95th instead of the 10-90th percentiles of distribution may be preferred to define minimum and maximum frequencies per week of foods and food (sub)groups to reach nutrient adequacy for as many nutrients as possible. Using the 10th and 90th percentiles resulted in draft FBR closer to the average food pattern, with the advantage that the population is asked to make less changes to their food patterns allowing for easier adoption of the developed FBR. However, the number of problem nutrients doubled compared to the 5-95th scenario. In order to still reach nutrient adequacy for the problem nutrients in the 10-90th scenario, alternative interventions that may be difficult to adopt by the population have to be considered. Using the 5-95th percentiles resulted in fewer problem nutrients and draft FBR still remained within the current local food patterns and may therefore be preferred to define minimum and maximum frequencies.

The number of recall days per child influenced the model input data, but did not affect the results of linear programming in our population. Minimum and maximum frequencies per week of foods and food (sub)groups used as model input data were more affected by the number of recall days when estimated consumption frequencies were used instead of reported frequencies. In addition, the food list was affected by the number of recall days 
per child. Using 1 instead of 2 recalls decreased the number of different foods consumed as expected, for scenarios using reported as well as estimated consumption frequencies. Conversely, the number of different foods included in the model increased using 1 instead of 2 recall days. As all foods with a maximum reported frequency (in the 95th percentile) of 0 consumptions per week were excluded from the food list, foods consumed on less than 6 out of 124 recall days (using both recall days) or 3 out of 62 recall days (using only 1 recall day) were not included in the model. In the recalls of the first day, 50 different foods were consumed of which 44 were consumed on at least 3 recall days. The recalls of the second day included slightly more foods (52 foods), however less foods were consumed on 3 or more recall days ( 36 foods) compared to the recalls of the first day. Using both recalls, 27 out of 64 foods were excluded, because these were consumed on less than 6 recall days. Reported consumption frequencies of the foods that were included in the food list of the first recall but excluded in the food list of both recalls were low. Consequently, reported minimum and maximum frequencies per week of foods and (sub) food (sub)groups used as model input data were only slightly different when 1 recall day was used instead of 2. Although the number of different foods was affected by the number of recall days when using reported consumption frequencies, the draft FBR and the number and type of problem nutrients were not affected by the number of recall days per child.

Assessing the habitual dietary intake of the population remains a challenge, especially in low- and middle-income countries, and results depend among others on the within- and between-person variation in dietary intake [45]. This variation is affected by many factors such as research area, season, age group and prevalence of overweight and undernutrition [46-48]. The present study was conducted in a rural area of Kenya with a prevalence of stunting of $23 \%$ in children under 5 years and a high prevalence of nutrient intake below the EAR, which is comparable with our study [49]. Within- and between-person variation in intake were higher for most nutrients in our population compared to the variation in intake of 6-11-year-old children in the NHANES study conducted in 2007-2008 [50]. This indicates that nutrient-dense foods are not consumed regularly (or daily) and not consumed by the whole population. This high variation may be related to the differences in poverty in our study area, where for example, expensive foods are only affordable for the relatively rich, contributing to the between-person variation, or can only be afforded irregularly, contributing to the within-person variation [50]. The relatively small number of children $(n=62)$ as well as the two dietary recalls per child only could have increased the estimated variation [50]. More recalls per child in a larger population will decrease the variation and tighten the distribution of consumption frequencies. In addition, the tightened distribution may reduce the differences in minimum and maximum frequencies between the scenarios. Smaller differences in the model input data will also reduce the differences in draft FBR and problem nutrients between the scenarios. Additional research with larger sample sizes and different target groups is needed to confirm the effect of variation on the results of linear programming.

\section{Conclusions}

In conclusion, our study shows that draft FBR and the type and number of identified problem nutrients are most sensitive to model input data related to frequency of consumption of foods and food (sub)groups. We recommend using reported consumption frequencies and collecting the frequency data of commonly as well as irregularly consumed foods to avoid over- or underestimation in dietary intake. To limit the number of problem nutrients, we suggest defining the minimum and maximum frequencies used as model input data by using the 5th and 95th percentile of the distribution. However, additional research is needed to test the eligibility of developed FBR using these percentiles. As the model input data based on the distribution of the frequencies may be affected by variation in diets, among others affected by a small sample size, the results of our study should be confirmed in other populations. 
Supplementary Materials: The following are available online at https:/ / www.mdpi.com/article/10 .3390/nu13103485/s1. Table S1: Median consumption frequencies per food group per week. Table S2: Median daily amount per food consumed by $>3 \%$ of the Kenyan children $4-6$ years of age, calculated from 2 recalls compared with 1 recall. Table S3: Minimum and maximum number of daily amounts per week required for linear programming in the reference scenario and 5 alternative 'dietary intake data' and 'selection criteria' scenarios for Kenyan children, 4-6 years of age.

Author Contributions: Conceptualisation, K.J.B.-v.d.B., J.H.M.d.V., E.J.M.F. and I.D.B.; methodology, K.J.B.-v.d.B., J.H.M.d.V. and I.D.B.; data curation, P.C.; field work supervision, K.J.B.-v.d.B. and I.D.B.; formal analysis and writing original draft, K.J.B.-v.d.B.; reviewing and editing, J.H.M.d.V., P.C., E.J.M.F., I.D.B. All authors have read and agreed to the published version of the manuscript.

Funding: This research received no external funding.

Institutional Review Board Statement: The effectiveness study was conducted according to the guidelines of the Declaration of Helsinki, registered at www.clinicaltrials.gov (NCT0216223), and approved by the Ethical Review Committee of Kenyatta National Hospital/Nairobi University (KNH-ERC/A/335) and ETH Zurich Ethical review committee (EK 2013-N-31).

Informed Consent Statement: Before the start of the study written informed consent has been obtained from the head of the household and the caregiver on behalf of the child.

Data Availability Statement: The data supporting the reported results are available on request from the corresponding author.

Acknowledgments: We thank the participants and their caregivers for their willingness to join the effectiveness study, and the interviewers and students for their support with field work.

Conflicts of Interest: The authors declare no conflict of interest.

\section{References}

1. Black, R.E.; Victora, C.G.; Walker, S.P.; Bhutta, Z.A.; Christian, P.; de Onis, M.; Ezzati, M.; Grantham-McGregor, S.; Katz, J.; Martorell, R.; et al. Maternal and child undernutrition and overweight in low-income and middle-income countries. Lancet 2013, 382, 427-451. [CrossRef]

2. Development Initiatives. 2020 Global Nutrition Report: Action on Equity to End Malnutrition; Development Initiatives: Bristol, UK, 2020.

3. Popkin, B.M.; Corvalan, C.; Grummer-Strawn, L.M. Dynamics of the double burden of malnutrition and the changing nutrition reality. Lancet 2020, 395, 65-74. [CrossRef]

4. Beal, T.; Massiot, E.; Arsenault, J.E.; Smith, M.R.; Hijmans, R.J. Global trends in dietary micronutrient supplies and estimated prevalence of inadequate intakes. PLoS ONE 2017, 12, e0175554. [CrossRef] [PubMed]

5. Gonzalez Fischer, C.; Garnett, T. Plates, Pyramids, Planet. Developments in National Healthy and Sustainable Dietary Guidelines: A State of Play Assessment; FAO: Rome, Italy; University of Oxford: Oxford, UK, 2016.

6. Keller, I.; Lang, T. Food-based dietary guidelines and implementation: Lessons from four countries-Chile, Germany, New Zealand and South Africa. Public Health Nutr. 2008, 11, 867-874. [CrossRef] [PubMed]

7. WHO; FAO. Preparation and Use of Food-Based Dietary Guidelines: Report of a Joint FAO/WHO Consultation; World Health Organisation: Geneva, Switzerland, 1998.

8. Van't Erve, I.; Tulen, C.B.M.; Jansen, J.; Van Laar, A.D.E.; Minnema, R.; Schenk, P.R.; Wolvers, D.; Van Rossum, C.T.M.; Verhagen, H. Overview of Elements within National Food-Based Dietary Guidelines. Eur. J. Nutr. Food Saf. 2017, 7, 172-227. [CrossRef]

9. Ferguson, E.; Chege, P.; Kimiywe, J.; Wiesmann, D.; Hotz, C. Zinc, iron and calcium are major limiting nutrients in the complementary diets of rural Kenyan children. Matern. Child Nutr. 2015, 11 (Suppl. (3), 6-20. [CrossRef]

10. Levesque, S.; Delisle, H.; Agueh, V. Contribution to the development of a food guide in Benin: Linear programming for the optimization of local diets. Public Health Nutr. 2015, 18, 622-631. [CrossRef]

11. Vossenaar, M.; Knight, F.A.; Tumilowicz, A.; Hotz, C.; Chege, P.; Ferguson, E.L. Context-specific complementary feeding recommendations developed using Optifood could improve the diets of breast-fed infants and young children from diverse livelihood groups in northern Kenya. Public Health Nutr. 2016, 20, 971-983. [CrossRef]

12. Wessells, K.R.; Young, R.R.; Ferguson, E.L.; Ouédraogo, C.T.; Faye, M.T.; Hess, S.Y. Assessment of Dietary Intake and Nutrient Gaps, and Development of Food-Based Recommendations, among Pregnant and Lactating Women in Zinder, Niger: An Optifood Linear Programming Analysis. Nutrients 2019, 11, 72. [CrossRef] [PubMed]

13. Chileshe, J.; Talsma, E.F.; Schoustra, S.E.; Borgonjen-van den Berg, K.J.; Handema, R.; Zwaan, B.J.; Brouwer, I.D. Potential contribution of cereal and milk based fermented foods to dietary nutrient intake of 1-5 years old children in Central province in Zambia. PLoS ONE 2020, 15, e0232824. [CrossRef] 
14. Samuel, A.; Osendarp, S.J.M.; Ferguson, E.; Borgonjen, K.; Alvarado, B.M.; Neufeld, L.M.; Adish, A.; Kebede, A.; Brouwer, I.D. Identifying Dietary Strategies to Improve Nutrient Adequacy among Ethiopian Infants and Young Children Using Linear Modelling. Nutrients 2019, 11, 1416. [CrossRef]

15. Buttriss, J.L.; Briend, A.; Darmon, N.; Ferguson, E.L.; Maillot, M.; Lluch, A. Diet modelling: How it can inform the development of dietary recommendations and public health policy. Nutr. Bull. 2014, 39, 115-125. [CrossRef]

16. FAO; WHO; UNU. Human Energy Requirements. Report of a Joint FAO/WHO/UNU Expert Consultation; Food and Agriculture Organization of the United Nations: Rome, Italy, 2004.

17. FAO. Fats and Fatty Acids in Human Nutrition. Report of an Expert Consultation; Food and Agriculture Organization of the United Nations: Rome, Italy, 2010.

18. Institute of Medicine. Dietary Reference Intakes: Applications in Dietary Assessment; National Academy Press: Washington, DC, USA, 2000.

19. European Food Safety Authority. Dietary Reference Values for Nutrients: Summary Report; EFSA Supporting Publication: Parma, Italy, 2017; Volume 14, p. e15121.

20. Vila-Real, C.; Pimenta-Martins, A.; Gomes, A.M.; Pinto, E.; Maina, N.H. How dietary intake has been assessed in African countries? A systematic review. Crit. Rev. Food Sci. Nutr. 2018, 58, 1002-1022. [CrossRef]

21. Gibson, R.S.; Ferguson, E.L. An Interactive $24 \mathrm{~h}$ Recall for Assessing the Adequacy of Iron and Zinc Intakes in Developing Countries; HarvestPlus, International Life Sciences Institute: Washington, DC, USA, 2008.

22. Hlaing, L.M.; Fahmida, U.; Htet, M.K.; Utomo, B.; Firmansyah, A.; Ferguson, E.L. Local food-based complementary feeding recommendations developed by the linear programming approach to improve the intake of problem nutrients among 12-23month-old Myanmar children. Br. J. Nutr. 2016, 116 (Suppl. (1), S16-S26. [CrossRef] [PubMed]

23. Kujinga, P.; Borgonjen-van den Berg, K.J.; Superchi, C.; Ten Hove, H.J.; Onyango, E.O.; Andang'o, P.; Galetti, V.; Zimmerman, M.B.; Moretti, D.; Brouwer, I.D. Combining food-based dietary recommendations using Optifood with zinc-fortified water potentially improves nutrient adequacy among 4- to 6-year-old children in Kisumu West district, Kenya. Matern. Child Nutr. 2017, 14, e12515. [CrossRef] [PubMed]

24. Skau, J.K.; Bunthang, T.; Chamnan, C.; Wieringa, F.T.; Dijkhuizen, M.A.; Roos, N.; Ferguson, E.L. The use of linear programming to determine whether a formulated complementary food product can ensure adequate nutrients for 6- to 11-month-old Cambodian infants. Am. J. Clin. Nutr. 2014, 99, 130-138. [CrossRef]

25. Talsma, E.F.; van den Berg, K.J.B.; Melse-Boonstra, A.; Mayer, E.V.; Verhoef, H.; Demir, A.Y.; Ferguson, E.L.; Kok, F.J.; Brouwer, I.D. The potential contribution of yellow cassava to dietary nutrient adequacy of primary-school children in Eastern Kenya; the use of linear programming. Public Health Nutr. 2017, 21, 365-376. [CrossRef]

26. Tharrey, M.; Olaya, G.A.; Fewtrell, M.; Ferguson, E. Adaptation of New Colombian Food-based Complementary Feeding Recommendations using Linear Programming. J. Pediatr. Gastroenterol. Nutr. 2017, 65, 667-672. [CrossRef]

27. Daelmans, B.; Ferguson, E.; Lutter, C.K.; Singh, N.; Pachon, H.; Creed-Kanashiro, H.; Woldt, M.; Mangasaryan, N.; Cheung, E.; Mir, R.; et al. Designing appropriate complementary feeding recommendations: Tools for programmatic action. Matern. Child Nutr. 2013, 9 (Suppl. (2), 116-130. [CrossRef]

28. Kujinga-Chopera, P. Effectiveness of Zinc Fortified Drinking Water on Zinc Intake, Status and Morbidity of Rural Kenyan Pre-School Children. Ph.D. Thesis, Wageningen University, Wageningen, The Netherlands, 2016.

29. Conway, J.M.; Ingwersen, L.A.; Vinyard, B.T.; Moshfegh, A.J. Effectiveness of the US Department of Agriculture 5-step multiplepass method in assessing food intake in obese and nonobese women. Am. J. Clin. Nutr. 2003, 77, 1171-1178. [CrossRef]

30. Sehmi, J.K. National Food Composition Tables and the Planning of Satisfactory Diets in Kenya; Government Press: Nairobi, Kenya, 1993.

31. Wolmarans, P.; Danster, N.; Dalton, A.; Rossouw, K.; Schönfeldt, H. Condensed Food Composition Tables for South Africa; Medical Research Council: Cape Town, South Africa, 2010.

32. Barikmo, I.; Ouattara, F.; Oshaug, A. Table de Composition des Aliments du Mali; Akerhus University College: Oslo, Norway, 2004.

33. USDA; ARS. USDA National Nutrient Database for Standard Reference, Release 27; USDA: Washington, DC, USA, 2014.

34. West, C.E.; Pepping, F.; Temalilwa, C.R. The Composition of Foods Commonly Eaten in East Africa; Wageningen University: Wageningen, The Netherlands, 1988.

35. USDA; ARS. USDA Table of Nutrient Retention Factors, Release 6; USDA: Washington, DC, USA, 2007.

36. Allen, L.; de Benoist, B.; Dary, O.; Hurrell, R. WHO/FAO Guidelines on Food Fortification with Micronutrients; World Health Organization: Geneva, Switzerland, 2006.

37. FANTA. Summary Report: Development of Evidence-Based Dietary Recommendations for Children, Pregnant Women, and Lactating Women Living in the Western Highlands in Guatemala; FHI 360/FANTA: Washington, DC, USA, 2013.

38. FAO; WHO. Human Vitamin and Mineral Requirements. Report of a Joint FAO/WHO Expert Consultation Bangkok, Thailand; Food and Agriculture Organization of the United Nations: Rome, Italy, 2001.

39. FAO; WHO; UNU. Protein and Amino Acid Requirements in Human Nutrition: Report of a Joint FAO/WHO/UNU Expert Consultation; World Health Organization: Geneva, Switzerland, 2007.

40. De Onis, M.; Onyango, A.W.; Borghi, E.; Siyam, A.; Nishida, C.; Siekmann, J. Development of a WHO growth reference for school-aged children and adolescents. Bull. World Health Organ. 2007, 85, 660-667. [CrossRef] 
41. WHO Multicentre Growth Reference Study Group. WHO Child Growth Standard: Length/Height-for-Age, Weight-for-Age, Weight-forLength, Weight-for-Height and Body Mass Index-for-Age: Methods and Development; World Health Organization: Geneva, Switzerland, 2006.

42. Coates, J.C.; Colaiezzi, B.A.; Bell, W.; Charrondiere, U.R.; Leclercq, C. Overcoming Dietary Assessment Challenges in Low-Income Countries: Technological Solutions Proposed by the International Dietary Data Expansion (INDDEX) Project. Nutrients 2017, 9 , 289. [CrossRef] [PubMed]

43. Subar, A.F.; Dodd, K.W.; Guenther, P.M.; Kipnis, V.; Midthune, D.; McDowell, M.; Tooze, J.A.; Freedman, L.S.; Krebs-Smith, S.M. The food propensity questionnaire: Concept, development, and validation for use as a covariate in a model to estimate usual food intake. J. Am. Diet. Assoc. 2006, 106, 1556-1563. [CrossRef] [PubMed]

44. Ost, C.; De Ridder, K.A.A.; Tafforeau, J.; Van Oyen, H. The added value of food frequency questionnaire (FFQ) information to estimate the usual food intake based on repeated $24 \mathrm{~h}$ recalls. Arch. Public Health 2017, 75, 46. [CrossRef]

45. Gibson, R.S.; Charrondiere, U.R.; Bell, W. Measurement Errors in Dietary Assessment Using Self-Reported 24 h Recalls in Low-Income Countries and Strategies for Their Prevention. Adv. Nutr. 2017, 8, 980-991. [CrossRef] [PubMed]

46. de Castro, M.A.; Verly, E., Jr.; Fisberg, M.; Fisberg, R.M. Children's nutrient intake variability is affected by age and body weight status according to results from a Brazilian multicenter study. Nutr. Res. 2014, 34, 74-84. [CrossRef] [PubMed]

47. Ollberding, N.J.; Couch, S.C.; Woo, J.G.; Kalkwarf, H.J. Within- and between-individual variation in nutrient intake in children and adolescents. J. Acad. Nutr. Diet. 2014, 114, 1749-1758.e1745. [CrossRef]

48. Stote, K.S.; Radecki, S.V.; Moshfegh, A.J.; Ingwersen, L.A.; Baer, D.J. The number of 24 h dietary recalls using the US Department of Agriculture's automated multiple-pass method required to estimate nutrient intake in overweight and obese adults. Public Health Nutr. 2011, 14, 1736-1742. [CrossRef]

49. Kenya National Bureau of Statistics; Ministry of Health/Kenya; National AIDS Control Council/Kenya; Kenya Medical Research Institute; National Council for Population Development/Kenya. Kenya Demographic and Health Survey 2014; Kenya National Bureau of Statistics: Rockville, MD, USA, 2015.

50. Willett, W. Nature of Variation in Diet. In Nutritional Epidemiology, 3rd ed.; Oxford University Press: New York, NY, USA, 2012. 